\title{
Sickle cell Anemia with avascular necrosis of femur being managed as rheumatic fever
}

\author{
Lamsal K.S. \\ Civil Service hospital, Minbhawan, Kathmandu, Nepal \\ Correspondence Address: Dr. Kamal Sharma Lamsal, Civil Service hospital, Minbhawan, Kathmandu, Nepal \\ Email: lamsalkamal@hotmail.com, Phone No: 014810412 (Res), 9851090676 ( mob)
}

\begin{abstract}
Sickle cell anemia is a rare hematological problem in Nepal and described only in the forms of case reports. This is a case report of a patient of sickle cell disease from Nawalparasi district of Nepal. The patient had history of recurrent joint pain including both large and small joints. He also had soft systolic murmur in cardiac auscultation for which he had received penicillin prophylaxis three years for clinically suspected rheumatic heart disease. He was later diagnosed to have Sickle cell anemia with avascular necrosis of right femoral head and functional murmur of severe anemia with no evidence of rheumatic heart disease.
\end{abstract}

Key words: avascular necrosis; rheumatic heart disease; sickle cell disease

\section{Introduction}

Sickle cell anemia, though a common medical problem in Africa and many other parts of the world. is a rare hematological problem in Nepal and described only in the forms of case reports. It is an autosomal recessive genetic disease that results from the substitution of valine for glutamic acid at position 6 of the beta-globin gene, leading to production of a defective form of hemoglobin, hemoglobin $\mathrm{S}(\mathrm{HbS})$. When deoxygenated, cells containing hemoglobin $\mathrm{S}$ assume sickle shape, as has been elucidated by high-resolution electron microscopy, 1 which become much less deformable and obstruct the microcirculation. Tissue hypoxia, which promotes further sickling, leads to vicious circle. Sickle-shaped RBCs are rapidly hemolyzed and have short life span leading to hemolytic anemia. Patients who are homozygous for the HbS gene have fullblown sickle cell anemia. The clinical manifestations of sickle cell anemia are diverse, and any organ system may be affected. These manifestations commonly are divided into vasoocclusive, hematologic, and infectious crises.

\section{Case Report}

An eighteen years old male patient presented to with the complaints of increased right hip pain for duration of six months. It was continuous with episodic exacerbations in and was none radiating. He also had limping and was counseled to be having short right leg. There was no history of trauma. Patient had received medication several times prior to our visit which did not help him much. He was referred to our center for further evaluation and management.

Patient gives history of exertional shortness of breath and palpitation on and of for last $7 / 8$ years. The patient also has history of yellowish discoloration of sclera on and off from the same duration. There is also history of occasional pain in right hip, back and hand joints for several years. He was also suspected to be a case of rheumatic fever and was taking injection penidura for prophylaxis for about three years. There was no significant family history.

On examination, patient was pale with icteric tinge. There was no cyanosis, clubbing, dehydration and lymphadenopathy. Vitals were stable except tachycardia. Chest examination was unremarkable; there was soft systolic mummer in mitral and pulmonary area. There was no splenomegaly and other per abdominal findings too were unremarkable. There was limping gait, tendelberg test was positive. There was about $2 \mathrm{~cm}$ true shorting of right leg. 
Hematological reports revealed Hb 6.7 gm\%, WBC 11400/ cumm with N61L25E14, ESR $47 \mathrm{~mm} / \mathrm{hr}$, reticulocyte count $15 \%$ and repeat value was $20 \%$. Peripheeral smear showed normochromic normocytic picture with plenty of target cells. Direct coombs test was negative. Random blood sugar, electrolytes and liver enzymes were within normal ranges but total bilirubin was $42 \mu \mathrm{mol} / 1$ with direct $8 \mu \mathrm{mol} / 1$ and LDH level was $701 \mathrm{mmol} / 1$. X-ray hip revealed collapsed femoral head with increased density (Fig 1). Iron profile revealed increased serum ferritin and USG abdomen showed multiple hypoechoic spleenic nodule and decreased spleen size suggestive of splenic atrophy. $\mathrm{Hb}$ electrophhorosis showed dark band of HBS ( Fig 2) and fade bands of HBF. Sickling of affected RBCs was found. Echocardiogram showed no abnormality with normal valvular apparatus and excluded rheumatic heart disease. The patient was kept on hydroxyurea for the management of sickle cell anemia.

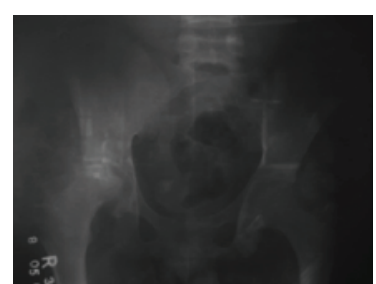

Fig 1: X-ray hip revealed collapsed femoral head with increased density

\section{Discussion}

Sickle cell anemia is a common medical problem in many parts of the world, whereas its very rare in Nepal. Its an autosomal recessive disease resulting from the substitution of valine for glutamic acid at position 6 of the betaglobin gene, leading to production of a defective form of hemoglobin, hemoglobin $\mathrm{S}(\mathrm{HbS})$. In deoxygenated form, cells containing hemoglobin $\mathrm{S}$ assume abnormal shapes including the commonest a banana or sickle shape, as has been elucidated by high-resolution electron microscopy. ${ }^{1}$ The polymerization of sickle hemoglobin is a remarkably dynamic event. The kinetic features of polymer formation are critical determinants of the shape and morphology of cells., ${ }^{2} 3$ The major consequence of this sickle shape is that RBCs become much less deformable; therefore, they obstruct the microcirculation. Tissue hypoxia, which promotes further sickling, results. Sickle-shaped RBCs are rapidly hemolyzed and have a life span of only 10-20 days (vs the normal $120 \mathrm{~d}$ ) leading to hemolytic anemia as seen in our patient. Patients who are homozygous for the $\mathrm{HbS}$ gene have full-blown sickle cell anemia. Patients who are heterozygous for the $\mathrm{HbS}$ gene are carriers of the condition as seen in father and siblings of our patient. The clinical manifestations of sickle cell anemia are diverse, and any organ system may be affected. These manifestations commonly are divided into vasoocclusive, hematologic, and infectious crises.

Because of its narrow vessels and function in clearing defective red blood cells, the spleen is frequently affected. It is usually infarcted before the end of childhood in individuals suffering from sickle-cell anemia, which in our case is demonstrated by multiple hypoechoic spleenic nodule and decreased spleen size suggestive of splenic atrophy. This autosplenectomy increases the risk of infection from encapsulated organism ${ }^{4,5}$ and preventive antibiotics and vaccinations are recommended for those with such asplenia. Aseptic necrosis is a condition of bone death that results from poor blood supply and is associated with alcoholism, cortisone medications, Cushing's syndrome, radiation exposure, sickle cell disease and systemic lupus erythematosus. Though it begins as a painless bone abnormality, the involved bone often later develops pain, especially with use i.e. weight-bearing. The diagnosis of aseptic necrosis can usually be made with x-rays. Earlier signs of avascular necrosis can be detected with an MRI scan or a nuclear bone scan. Management involves analgesia and joint replacement. ${ }^{6,7}$ There is no definitive treatment for sickle cell disease. $\mathrm{Zn}$ administration is useful to stablise the cell membrane. ${ }^{8}$ Patients presenting with fever are screened for bacteremia and treated with antibiotics. Painful crises are treated symptomatically with analgesics; pain management may require opioid administration at regular intervals. For milder crises a subgroup of patients are managed on NSAIDs (such as diclofenac or naproxen). For acute chest crisis management is similar to vasoocclusive crises with the addition of antibiotics (usually a quinolone or macrolide, since wall-deficient ["atypical"] bacteria are thought to contribute to the syndrome), ${ }^{9}$ oxygen supplementation for hypoxia, and close observation. Should the pulmonary infiltrate worsen or the oxygen requirements increase, simple blood transfusion or exchange transfusion is indicated. Hydroxyurea, was shown to decrease the number and severity of attacks in a study in 1995 (Charache et al) ${ }^{10}$ and to increase survival time in a study in 2003 (Steinberg et al). ${ }^{11}$ This is achieved, in part, by reactivating fetal hemoglobin production in place of the hemoglobin $\mathrm{S}$ that causes sickling.

\section{References}

1. Dykes GW, Crepeau RH, Edelstein SJ. Threedimensional reconstruction of the 14-filament fibers of hemoglobin S. J Mol Biol 1979; 130:451-472. 
2. Mozzarelli A, Hofrichter J, Eaton WA. Delay time of hemoglobin S polymerization prevents most cells from sickling in vivo. Science 1987; 237:500-506.

3. Asakura T, Mattiello JA, Obata K et al. Partially oxygenated sickled cells: sickle-shaped red cells found in circulating blood of patients with sickle cell disease. Proc Natl Acad Sci U S A 1994; 91:1258912593.

4. Pearson H. "Sickle cell anaemia and severe infections due to encapsulated bacteria". J Infect Dis 136 Suppl: S25-30.

5. Wong W, Powars D, Chan L et al (1992). "Polysaccharide encapsulated bacterial infection in sickle cell anaemia: a thirty year epidemiologic experience". Am J Hematol1992. 39 (3): 176-82.

6. Lippincott Williams \& Wilkens Clinical Primer of Rheumatology, edited by William Koopman et al., 2003.

7. W B Saunders Co. Kelley's Textbook of Rheumatology, edited by Shaun Ruddy et.al. 2000.

8. Tocco-Bradley R \& M J Kluger. "Zinc concentration and survival in rats infected with Salmonella typhimurium". Infection and Immunity 45 (2): 332-338. Retrieved on 2007-11-17.

9. Aldrich TK\& Nagel RL. "Pulmonary Complications of Sickle Cell Disease.", Pulmonary and Critical Care Medicine, 6th edition, St. Louis:

10. Charache, Samuel, Terrin ML et al. "Effect of hydroxyurea on the frequency of painful crises in sickle cell anaemia. Investigators of the Multicenter Study of Hydroxyurea in Sickle Cell anaemia". NEJM 332 (20): 1317-1322.

11. Steinberg, Martin H \& Barton F. "Effect of hydroxyurea on mortality and morbidity in adult sickle cell anaemia: risks and benefits up to 9 years of treatment". JAMA 289 (13): 16451651. 